\title{
Aluminum oxide free-standing thin films to enable nitrogen edge soft x-ray scattering
}

\author{
Dan Ye, Sintu Rongpipi, Joshua H. Litofsky, Youngmin Lee, Tyler E. Culp, and Sang Ha Yoo, Department of Chemical Engineering, \\ The Pennsylvania State University, University Park, PA 16802, USA \\ Thomas N. Jackson, Department of Electrical Engineering, The Pennsylvania State University, University Park, PA 16802, USA \\ Cheng Wang, Advanced Light Source, Lawrence Berkeley National Laboratory, 1 Cyclotron Road, Berkeley, CA 94720, USA \\ Esther W. Gomez, Department of Chemical Engineering, The Pennsylvania State University, University Park, PA 16802, USA; Department of Biomedical \\ Engineering, The Pennsylvania State University, University Park, PA 16802, USA \\ Enrique D. Gomez, Department of Chemical Engineering, The Pennsylvania State University, University Park, PA 16802, USA; Department of Materials \\ Science and Engineering and Materials Research Institute, The Pennsylvania State University, University Park, PA 16802, USA
}

Address all correspondence to Esther W. Gomez, Enrique D. Gomez at ewg10@psu.edu, edg12@psu.edu

(Received 18 July 2018; accepted 5 September 2018)

\begin{abstract}
Resonant soft x-ray scattering (RSOXS) leverages chemical specificity to characterize thin films but is limited near the nitrogen edge. The challenge is that commercially available $x$-ray transparent substrates are composed of $\mathrm{Si}_{3} \mathrm{~N}_{4}$ and thereby absorb incident $\mathrm{x}$-rays and generate incoherent fluorescence. To overcome this challenge, we designed and fabricated $\mathrm{Al}_{2} \mathrm{O}_{3}$ free-standing films for use as $\mathrm{RS}$ XXS windows. $\mathrm{Al}_{2} \mathrm{O}_{3}$ films offer higher $\mathrm{x}$-ray transmittance and minimal fluorescence near the nitrogen edge. As an example, $\mathrm{Al}_{2} \mathrm{O}_{3}$ windows allow for nitrogen $\mathrm{RS}$ XS of conjugated block copolymer thin films that reveal domain spacings, which are not apparent with commercially available $\mathrm{Si}_{3} \mathrm{~N}_{4}$ substrates.
\end{abstract}

Resonant soft x-ray scattering (RSoXS) is a relatively new technique that can provide structural information about organic thin films with chemical sensitivity. Pioneering work demonstrated that transmission soft $\mathrm{x}$-ray scattering experiments can reveal the 20 to $30 \mathrm{~nm}$ domain spacing in microphase-separated polystyrene- $b$-polyisoprene thin films by working at resonance with the $1 \mathrm{~s} \rightarrow \pi^{*}(\mathrm{C}=\mathrm{C})$ transition. ${ }^{[1]}$ Further work has transformed our understanding of the microstructure in polymer/ fullerene mixtures ${ }^{[2-5]}$ and conjugated block copolymers (BCPs) used in photovoltaics ${ }^{[6]}$ by identifying length scales for phase or microphase separation, and has resulted in new structural models for biomolecules in solution, such as casein micelles ${ }^{[7,8]}$ and bovine serum albumin. ${ }^{[9]}$ Most RSoXS data to date are generated at the carbon edge,${ }^{[10]}$ with a few exceptions of studies that include the oxygen ${ }^{[11,12]}$ and calcium edges. ${ }^{[7,13]}$

Despite the opportunity to examine the distribution of nitrogen $(\mathrm{N})$ in organic and biological compounds, very few studies have employed RSoXS at the $\mathrm{N}$ edge. ${ }^{[14]}$ The challenge lies in the $\mathrm{x}$-ray transparent support, which is $50-100 \mathrm{~nm}$ thick $\mathrm{Si}_{3} \mathrm{~N}_{4}$ that produces a significant RSoXS background at energies near the $\mathrm{N}$ edge. These $\mathrm{Si}_{3} \mathrm{~N}_{4}$ supports are formed through a lowpressure chemical vapor deposition (LPCVD) process and have Young's moduli between 140 and $290 \mathrm{GPa}^{[15]}$ with a fracture toughness of about $6 \mathrm{MPa} \cdot \mathrm{m}^{0.5} \cdot{ }^{[16]}$ These mechanical properties allow fabricated free-standing $\mathrm{Si}_{3} \mathrm{~N}_{4}$ windows with a $1 \mathrm{~mm} \times 1 \mathrm{~mm}$ opening to have a thickness of approximately
$50 \mathrm{~nm}$ and enable the construction of liquid sample cells that can withstand the high vacuum in the RSoXS sample chamber. ${ }^{[7,9]}$ Nevertheless, fluorescence at the $\mathrm{N}$ edge when using $\mathrm{Si}_{3} \mathrm{~N}_{4}$ supports adds a significant incoherent background and confounds RSoXS studies.

As an alternative to $\mathrm{Si}_{3} \mathrm{~N}_{4}$, we designed and fabricated $\mathrm{Al}_{2} \mathrm{O}_{3}$ windows for RSoXS experiments. Atomic layer deposition (ALD) leads to $\mathrm{Al}_{2} \mathrm{O}_{3}$ films with Young's moduli near 200 $\mathrm{GPa}^{[17]}$ and a fracture toughness of about $2 \mathrm{MPa} \cdot \mathrm{m}^{0.5},{ }^{[18]}$ which is comparable with values from $\mathrm{LPCVD} \mathrm{Si}_{3} \mathrm{~N}_{4}$ films. These mechanical properties enabled the fabrication of $46 \mathrm{~nm}$ thick free-standing $\mathrm{Al}_{2} \mathrm{O}_{3}$ films that have higher x-ray transmittance than commercially available $50 \mathrm{~nm}$ thick $\mathrm{Si}_{3} \mathrm{~N}_{4}$. Using $\mathrm{Al}_{2} \mathrm{O}_{3}$ films as X-ray windows, we demonstrated RSoXS at the N K-edge for a poly(3-hexylthiophene-2,5-diyl)-block-poly ((9,9-bis-(2-octyl) fluorene-2,7-diyl)-alt-(4,7-di(thiophene-2yl)-21,3-benzothiadiazole)-5',5"-diyl) BCP (P3HT-b-PFTBT). RSoXS of P3HT- $b$-PFTBT supported on $\mathrm{Al}_{2} \mathrm{O}_{3}$ windows reveals a structural feature at the $\mathrm{N} \mathrm{K}$-edge that is not observed using $\mathrm{Si}_{3} \mathrm{~N}_{4}$ supports due to the fluorescence background from $\mathrm{Si}_{3} \mathrm{~N}_{4}$.

Suitable substrates for soft $\mathrm{x}$-ray scattering experiments require a x-ray transparent film and a support structure. Our approach relies on patterning $\mathrm{Al}_{2} \mathrm{O}_{3}$ films that are deposited on silicon wafers as shown in Fig. 1. The RSoXS substrate design contains $5 \mathrm{~mm} \times 5 \mathrm{~mm}$ squares as the silicon frame with a $1.7 \mathrm{~mm}$-diameter circle in the center of each square as 


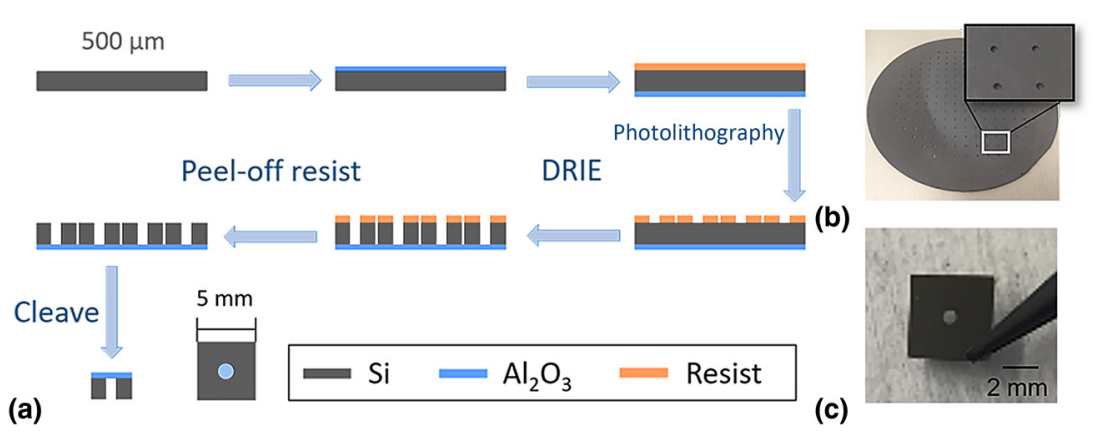

Figure 1. Fabrication of $\mathrm{Al}_{2} \mathrm{O}_{3}$ windows by atomic layer deposition and photolithography. (a) Schematic of $\mathrm{Al}_{2} \mathrm{O}_{3}$ window fabrication process. (b) A 4-inch wafer

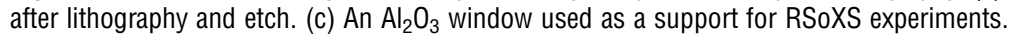

the $\mathrm{Al}_{2} \mathrm{O}_{3}$ window. $\mathrm{Al}_{2} \mathrm{O}_{3}$ films were grown on a 4-inch silicon wafer through ALD and patterns were transferred to the $\mathrm{Al}_{2} \mathrm{O}_{3}$-coated wafer through photolithography. After photolithography, the silicon covering the circular patterned area was back etched using deep reactive-ion etching, which leaves an $\mathrm{Al}_{2} \mathrm{O}_{3}$ free-standing film with a diameter of approximately 1 $\mathrm{mm}$. Following the nanofabrication process, resist was removed and the wafers were cleaved into individual $\mathrm{Al}_{2} \mathrm{O}_{3}$ windows. Spectroscopic ellipsometry revealed an $\mathrm{Al}_{2} \mathrm{O}_{3}$ window thickness of $46 \mathrm{~nm}$. AFM images shown in Figure $\mathrm{S} 1$ of the Supplementary material reveal that the roughness of $\mathrm{Al}_{2} \mathrm{O}_{3}$ films is similar to the roughness of commercially available $\mathrm{Si}_{3} \mathrm{~N}_{4}$ films. Nevertheless, shallow long depressions (trenches) are apparent in $\mathrm{Al}_{2} \mathrm{O}_{3}$, although the origin of these features is unclear.

The $\mathrm{x}$-ray transmittance and scattering of $\mathrm{Al}_{2} \mathrm{O}_{3}$ windows as compared with $\mathrm{Si}_{3} \mathrm{~N}_{4}$ windows were tested using RSoXS. As shown in Fig. 2(a), the X-ray transmittance spectra indicate that the $46 \mathrm{~nm}$ thick $\mathrm{Al}_{2} \mathrm{O}_{3}$ windows absorb less $\mathrm{x}$-rays than the $50 \mathrm{~nm}$ thick $\mathrm{Si}_{3} \mathrm{~N}_{4}$ windows. The scattering profile from the $\mathrm{Al}_{2} \mathrm{O}_{3}$ film has no structural peaks near the carbon K-edge [Fig. 2(b)] or the nitrogen K-edge [Fig. 2(c)], as expected. Data at the onset of the nitrogen K-edge (398.2 eV) is shown in Figure S2 of the Supplementary material. Scattering from the $46 \mathrm{~nm}$ thick $\mathrm{Al}_{2} \mathrm{O}_{3}$ window has lower intensity at high $q\left(q>0.01 \AA^{-1}\right)$ than scattering from the 50 $\mathrm{nm}$ thick $\mathrm{Si}_{3} \mathrm{~N}_{4}$ window. The higher scattering intensity from $\mathrm{Al}_{2} \mathrm{O}_{3}$ at low $q\left(q<0.01 \AA^{-1}\right)$ could arise because the scattering contrast between $\mathrm{Al}_{2} \mathrm{O}_{3}$ and vacuum is higher than the scattering contrast between $\mathrm{Si}_{3} \mathrm{~N}_{4}$ and vacuum (Figure $\mathrm{S} 3$ of the Supplementary material), such that any surface roughness of the $\mathrm{Al}_{2} \mathrm{O}_{3}$ window contributes more strongly to scattering. Alternatively, the $\mathrm{Al}_{2} \mathrm{O}_{3}$ windows may have more residual contaminants on their surfaces left from the photolithography process, or the long shallow trenches apparent throughout the samples (Figure S1 of the Supplementary material) could contribute to scattering at low $q$.

A challenge presented by commercially available $\mathrm{Si}_{3} \mathrm{~N}_{4}$ windows traditionally used for RSoXS studies is that they generate a high incoherent fluorescence background. X-ray emission that follows ionization generates a $q$ independent constant in the scattering profile. Using a simple model, the influence of fluorescence background on scattering profiles is demonstrated in Figure S4 of the Supplementary material. As the fluorescence background increases, the $I(q) q^{2}$ profile starts to have a more pronounced upturn in the high $q$ region $\left(q>0.02 \AA^{-1}\right)$ that can mask structural features of the sample. As shown in Figure $\mathrm{S} 5 \mathrm{a}$ of the Supplementary material, $\mathrm{Al}_{2} \mathrm{O}_{3}$ has a similar scattering profile at the $\mathrm{C} \mathrm{K}$-edge and the $\mathrm{N}$ K-edge with no significant upturn. On the other hand, the scattering profile of $\mathrm{Si}_{3} \mathrm{~N}_{4}$ becomes nearly constant above $q=0.01 \AA^{-1}$ at the $\mathrm{C}$ K-edge while there is an upturn near $q=0.02 \AA^{-1}$ at the N K-edge (Figure S5b of the Supplementary material). The upturn is attributed to fluorescence emission from $\mathrm{N}$ atoms in $\mathrm{Si}_{3} \mathrm{~N}_{4}$. Thus, the $\mathrm{Al}_{2} \mathrm{O}_{3}$ windows offer a clear advantage over $\mathrm{Si}_{3} \mathrm{~N}_{4}$ at the $\mathrm{N}$ edge for RSoXS studies.

We use P3HT- $b$-PFTBT as a model system to demonstrate the utility of $\mathrm{Al}_{2} \mathrm{O}_{3}$ windows for characterizing the morphology of nitrogen-containing materials. P3HT- $b$-PFTBT is a conjugated $\mathrm{BCP}$ with record performance as a single-component active layer in organic solar cell devices. ${ }^{[6]}$ Previous work has demonstrated that P3HT- $b$-PFTBT microphase separates into a lamellar morphology with a domain spacing of about $20 \mathrm{~nm}$ that depends on the molecular weight. ${ }^{[6,19,20]}$ P3HT- $b$ PFTBT was synthesized using previously published methods. ${ }^{[21]}$ As shown in Fig. 3(a), there are two nitrogen atoms per monomer in the PFTBT block. The NEXAFS spectra of the homopolymers (P3HT and PFTBT) and the BCP (P3HT- $b$-PFTBT) are plotted in Fig. 3(b). All three polymers have strong absorption near the carbon K-edge, and the sharp peak near $285 \mathrm{eV}$ corresponds to the $1 \mathrm{~s} \rightarrow \pi^{*}$ transitions of the $\mathrm{C}=\mathrm{C}$ bonds. Near the nitrogen edge ( 380 to $420 \mathrm{eV})$, there is no feature in the P3HT NEXAFS spectra while there are absorption features in the PFTBT and P3HT- $b$-PFTBT spectra from the nitrogen atoms of PFTBT. The absorption is less apparent in P3HT- $b$-PFTBT because the number density of nitrogen is lower than it is in PFTBT. Nevertheless, the difference in NEXAFS spectra between P3HT and PFTBT due to the 

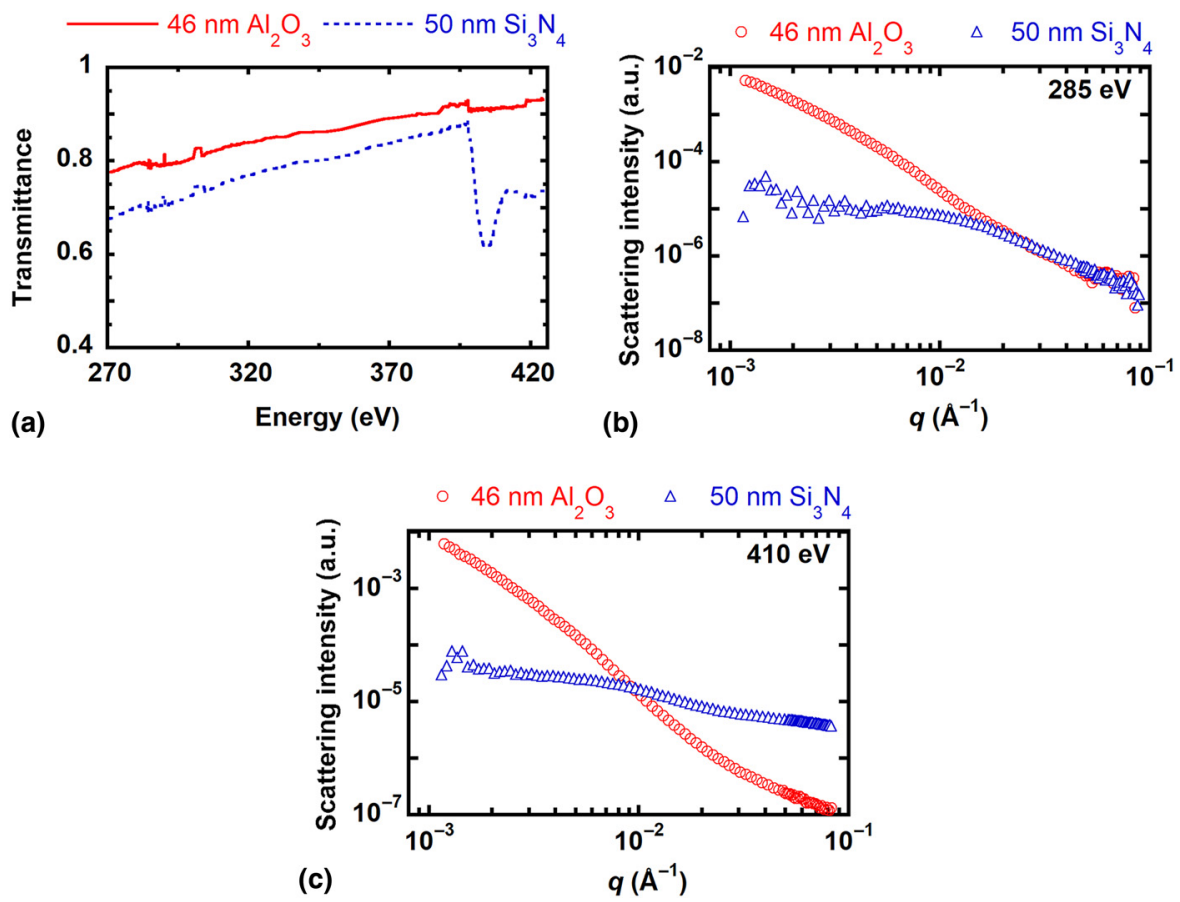

Figure 2. Absorption and scattering profiles of $46 \mathrm{~nm}$ thick $\mathrm{Al}_{2} \mathrm{O}_{3}$ and $50 \mathrm{~nm}$ thick $\mathrm{Si}_{3} \mathrm{~N}_{4}$ substrates. (a) NEXAFS spectra near the carbon and nitrogen $\mathrm{K}$-edges. Scattering profiles at (b) $285 \mathrm{eV}$ (carbon K-edge) and (c) $410 \mathrm{eV}$ (nitrogen K-edge).

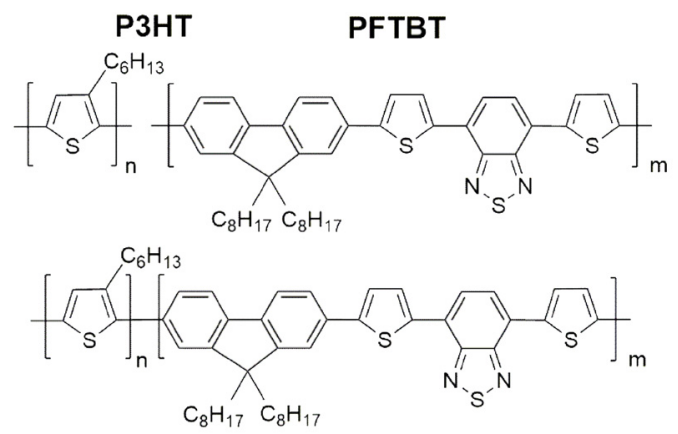

(a)

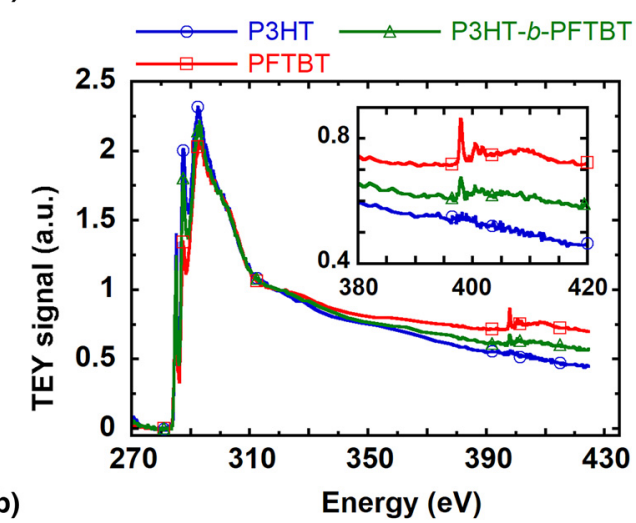

Figure 3. A model system for N RSoXS experiments. (a) Chemical structures and (b) Total Electron Yield (TEY) NEXAFS spectra of P3HT, PFTBT, and P3HT- $b$-PFTBT. The inset highlights spectra near the N edge. lack of nitrogen in P3HT should lead to significant RSoXS contrast at the $\mathrm{N}$ edge.

Scattering profiles of P3HT- $b$-PFTBT thin films supported on $\mathrm{Al}_{2} \mathrm{O}_{3}$ windows and supported on commercially available $\mathrm{Si}_{3} \mathrm{~N}_{4}$ windows are presented in Fig. 4 . The background scattering from $\mathrm{Al}_{2} \mathrm{O}_{3}$ or $\mathrm{Si}_{3} \mathrm{~N}_{4}$ windows was subtracted from the data. As shown in Fig. 4(a), the scattering profiles near the carbon $\mathrm{K}$-edge $(285 \mathrm{eV})$ of P3HT- $b$-PFTBT supported on $\mathrm{Al}_{2} \mathrm{O}_{3}$ or $\mathrm{Si}_{3} \mathrm{~N}_{4}$ are very similar. The structural feature near $q=0.03$ $\AA^{-1}$ corresponds to $20 \mathrm{~nm}$ and indicates that P3HT and PFTBT have distinct nanoscale domains that are separated by $20 \mathrm{~nm}$ on average. This feature near $q=0.03 \AA^{-1}$ becomes more apparent in the Kratky plot $\left(I q^{2}\right.$ versus $\left.q\right)$ shown in Fig. 4(b), although an overall positive slope for the entire profile that is likely indicative of fluorescence from the polymer film is apparent.

Near the nitrogen edge $(410 \mathrm{eV})$, there is a clear feature at approximately $q=0.02 \AA^{-1}$ corresponding to about $30 \mathrm{~nm}$ in the scattering profile of P3HT- $b$-PFTBT supported on $\mathrm{Al}_{2} \mathrm{O}_{3}$ windows that is not present when measurements are taken using $\mathrm{Si}_{3} \mathrm{~N}_{4}$ windows [Fig. 4(c)]. Data are also shown at the onset of the nitrogen edge $(398.2 \mathrm{eV})$ in Figure $\mathrm{S} 6$ of the Supplementary material. When $\mathrm{Si}_{3} \mathrm{~N}_{4}$ is used as a substrate, the background corrected Kratky plot has an overall positive slope with an upturn at high $q$ starting from $q=0.03 \AA^{-1}$, as shown in Fig. 4(d). The upturn at high $q$ in $I q^{2}$ is often a signature of a fluorescence ( $q$-independent) background. Furthermore, when $\mathrm{Si}_{3} \mathrm{~N}_{4}$ windows are used, the scattering 

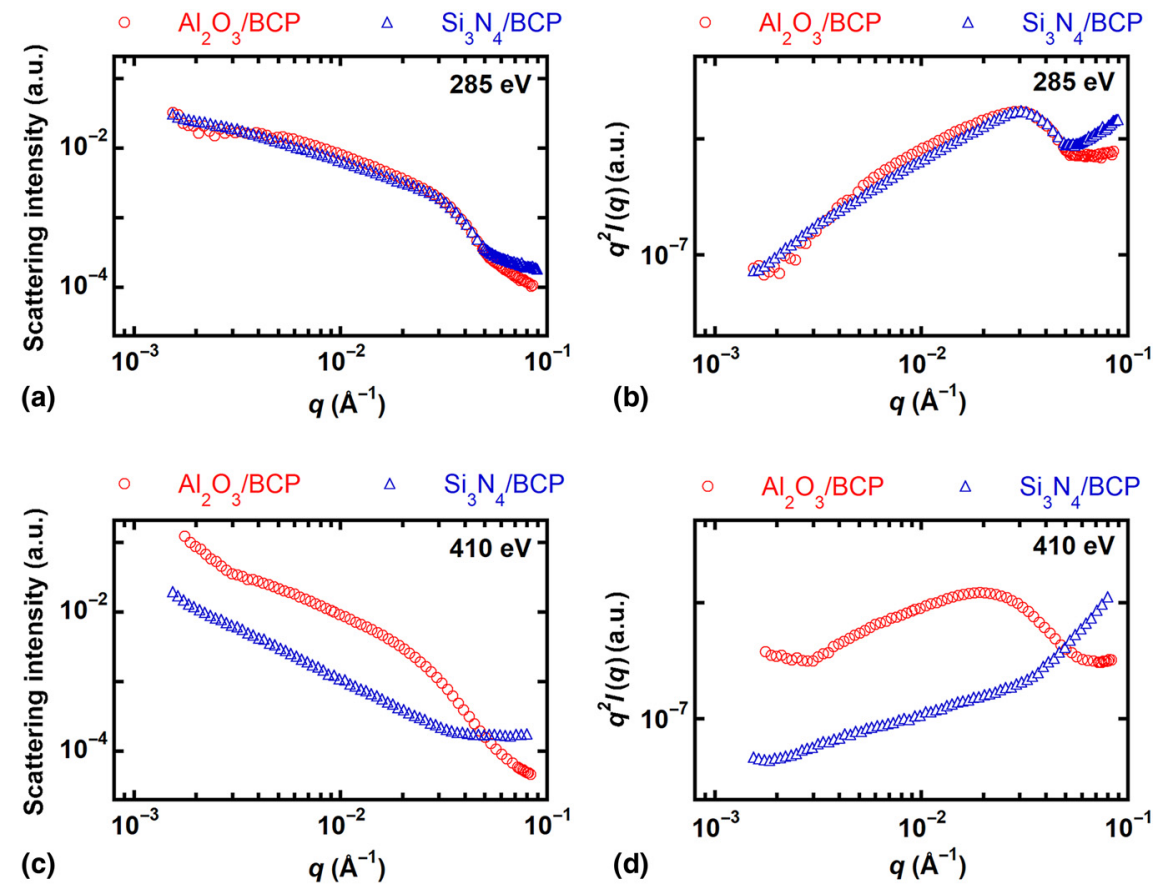

Figure 4. RSoXS profiles and Kratky plots of scattering from a P3HT-b-PFTBT block copolymer (BCP) supported on a $46 \mathrm{~nm}$ thick $\mathrm{Al}_{2} \mathrm{O}_{3}$ substrate or a $50 \mathrm{~nm}$ thick $\mathrm{Si}_{3} \mathrm{~N}_{4}$ substrate near the (a), (b) carbon K-edge $(285 \mathrm{eV})$ and the (c), (d) nitrogen K-edge $(410 \mathrm{eV})$.

profile at $285 \mathrm{eV}$ reveals peaks associated with the microstructure of P3HT- $b$-PFTBT [Figs. 4(a) and 4(b)], but these peaks are not apparent at the $\mathrm{N}$ edge [Figs. 4(c) and 4(d)]. We thus speculate that scattering is re-absorbed and emitted as incoherent fluorescence when $\mathrm{Si}_{3} \mathrm{~N}_{4}$ windows are used at the $\mathrm{N}$ edge.

When comparing the data collected at the carbon and nitrogen edge from $\mathrm{BCP}$ films with $\mathrm{Al}_{2} \mathrm{O}_{3}$ supports, there is a disagreement in terms of the apparent domain spacing (at $q=$ 0.03 and $0.02 \AA^{-1}$, respectively). Near the nitrogen edge, the scattering contrast is between P3HT and PFTBT domains, but near the carbon edge, the scattering contrast is more complicated. Because RSoXS is sensitive to differences in chain orientation and the $1 \mathrm{~s} \rightarrow \pi^{*}$ transition dipole moment is anisotropic, we speculate that the structure between crystalline and amorphous P3HT leads to scattering peaks at a higher $q .^{[22,23]}$ Thus, the combination of $\mathrm{C}$ and $\mathrm{N}$ RSoXS reveals multiple aspects of the microstructure of P3HT- $b$-PFTBT films, including a center-to-center spacing of crystallites within P3HT domains of $20 \mathrm{~nm}$ and a spacing between P3HT and PFTBT domains of $30 \mathrm{~nm}$.

In summary, we demonstrate that free standing $46 \mathrm{~nm}$ thick $\mathrm{Al}_{2} \mathrm{O}_{3}$ films enable examination of the structure of nitrogencontaining materials using RSoXS. $\mathrm{Al}_{2} \mathrm{O}_{3}$ windows reduce parasitic absorption and eliminate the fluorescence background near the nitrogen edge. As a consequence, structural features of P3HT- $b$-PFTBT are revealed near the nitrogen edge on $\mathrm{Al}_{2} \mathrm{O}_{3}$ substrates, even though such features are not apparent using commercial $\mathrm{Si}_{3} \mathrm{~N}_{4}$ substrates. Fabricating x-ray transparent substrates, such as $\mathrm{Al}_{2} \mathrm{O}_{3}$ films, will enable RSoXS studies focused on nitrogen-containing systems that include some organic semiconductors, membrane proteins, and proteinnucleic acids complexes.

\section{Supplementary material}

The supplementary material for this article can be found at https://doi.org/10.1557/mrc.2018.195.

\section{Acknowledgments}

Financial support from NSF MRI-1626566 (E.D.G.) and the Grace Woodward Grant for Collaborative Research in Engineering and Medicine (E.W.G.) is acknowledged. D.Y. acknowledges support by an Advanced Light Source Doctoral Fellowship in Residence. The Advanced Light Source is supported by the Director, Office of Science, Office of Basic Energy Sciences, of the US Department of Energy under Contract No. DE-AC02-05CH11231. The authors thank Chad Eichfeld and Guy Lavallee for their help with the design of the lithography mask and etch process.

\section{References}

1. J.M. Virgili, Y.F. Tao, J.B. Kortright, N.P. Balsara, and R.A. Segalman: Analysis of order formation in block copolymer thin films using resonant soft x-ray scattering. Macromolecules 40, 2092 (2007).

2. J.R. Tumbleston, B.A. Collins, L. Yang, A.C. Stuart, E. Gann, W. Ma, W. You, and $\mathrm{H}$. Ade: The influence of molecular orientation on organic bulk heterojunction solar cells. Nat. Photonics 8, 385 (2014). 
3. B.A. Collins, Z. Li, J.R. Tumbleston, E. Gann, C.R. McNeill, and H. Ade: Absolute measurement of domain composition and nanoscale size distribution explains performance in PTB7:PC71BM solar cells. Adv. Energy. Mater. 3, 65 (2013).

4. F. Liu, M.A. Brady, and C. Wang: Resonant soft x-ray scattering for polymer materials. Eur. Polym. J. 81, 555 (2016).

5. S. Swaraj, C. Wang, H.P. Yan, B. Watts, L.N. Jan, C.R. McNeill, and $H$. Ade: Nanomorphology of bulk heterojunction photovoltaic thin films probed with resonant soft x-ray scattering. Nano Lett. 10, 2863 (2010).

6. C. Guo, Y.-H. Lin, M.D. Witman, K.A. Smith, C. Wang, A. Hexemer, J. Strzalka, E.D. Gomez, and R. Verduzco: Conjugated block copolymer photovoltaics with near $3 \%$ efficiency through microphase separation. Nano Lett. 13, 2957 (2013).

7. B. Ingham, G.D. Erlangga, A. Smialowska, N.M. Kirby, C. Wang, L. Matia-Merino, R.G. Haverkamp, and A.J. Carr: Solving the mystery of the internal structure of casein micelles. Soft Matter 11, 2723 (2015).

8. B. Ingham, A. Smialowska, G.D. Erlangga, L. Matia-Merino, N.M. Kirby, C. Wang, R.G. Haverkamp, and A.J. Carr: Revisiting the interpretation of casein micelle SAXS data. Soft Matter 12, 6937 (2016).

9. D. Ye, T.P. Le, B. Kuei, C. Zhu, P.H. Zwart, C. Wang, E.D. Gomez, and E.W. Gomez: Resonant soft $x$-ray scattering provides protein structure with chemical specificity. Structure (2018) https://doi.org/10.1016/j.str. 2018.07.018.

10.E. Gann, A.T. Young, B.A. Collins, H. Yan, J. Nasiatka, H.A. Padmore, $H$. Ade, A. Hexemer, and C. Wang: Soft x-ray scattering facility at the advanced light source with real-time data processing and analysis. Rev. Sci. Instrum. 83, 045110 (2012).

11. C. Guo, D.R. Kozub, S.V. Kesava, C. Wang, A. Hexemer, and E.D. Gomez: Signatures of multiphase formation in the active layer of organic solar cells from resonant soft x-ray scattering. ACS Macro Lett. 2, 185 (2013).

12. J.B. Kortright, J. Sun, R.K. Spencer, X. Jiang, and R.N. Zuckermann: Oxygen $\mathrm{K}$ edge scattering from bulk comb diblock copolymer reveals extended, ordered backbones above lamellar order-disorder transition. J. Phys. Chem. B 121, 298 (2016).

13.D. Ye, S.N. Kiemle, S. Rongpipi, X. Wang, C. Wang, D.J. Cosgrove, E.W. Gomez, and E.D. Gomez: Resonant soft x-ray scattering reveals cellulose microfibril spacing in plant primary cell walls. Sci. Rep. 8, 12449 (2018).

14. M.A. Brady, S.-Y. Ku, L.A. Perez, J.E. Cochran, K. Schmidt, T.M. Weiss, M.F. Toney, H. Ade, A. Hexemer, C. Wang, C.J. Hawker, E.J. Kramer, and M.L. Chabinyc: Role of solution structure in self-assembly of conjugated block copolymer thin films. Macromolecules 49, 8187 (2016).

15. A. Khan, J. Philip, and P. Hess: Young's modulus of silicon nitride used in scanning force microscope cantilevers. J. Appl. Phys. 95, 1667 (2004).

16. B. Merle, and M. Göken: Fracture toughness of silicon nitride thin films of different thicknesses as measured by bulge tests. Acta Mater. 59, 1772 (2011).

17. M.K. Tripp, C. Stampfer, D.C. Miller, T. Helbling, C.F. Herrmann, C. Hierold, K. Gall, S.M. George, and V.M. Bright: The mechanical properties of atomic layer deposited alumina for use in micro- and nanoelectromechanical systems. Sens. Actuator A-Phys. 130-131, 419 (2006).

18. D.C. Miller, R.R. Foster, Y. Zhang, S.-H. Jen, J.A. Bertrand, Z. Lu, D. Seghete, J.L. O'Patchen, R. Yang, Y.-C. Lee, S.M. George, and M.L. Dunn: The mechanical robustness of atomic-layer- and molecular-layer-deposited coatings on polymer substrates. J. Appl. Phys. 105, 093527 (2009)

19. C. Guo, Y. Lee, Y.-H. Lin, J. Strzalka, C. Wang, A. Hexemer, C. Jaye, D.A. Fischer, R. Verduzco, Q. Wang, and E.D. Gomez: Photovoltaic performance of block copolymer devices is independent of the crystalline texture in the active layer. Macromolecules 49, 4599 (2016).

20. C. Grieco, M.P. Aplan, A. Rimshaw, Y. Lee, T.P. Le, W. Zhang, Q. Wang, S.T. Milner, E.D. Gomez, and J.B. Asbury: Molecular rectification in conjugated block copolymer photovoltaics. J. Phys. Chem. C 120, 6978 (2016).

21. Y. Lee, M.P. Aplan, Z.D. Seibers, S.M. Kilbey, Q. Wang, and E.D. Gomez: Tuning the synthesis of fully conjugated block copolymers to minimize architectural heterogeneity. J. Mater. Chem. A 5, 20412 (2017).
22. K. Vakhshouri, B.H. Smith, E.P. Chan, C.C. Wang, A. Salleo, C. Wang, A. Hexemer, and E.D. Gomez: Signatures of intracrystallite and intercrystallite limitations of charge transport in polythiophenes. Macromolecules 49, 7359 (2016).

23. B.A. Collins, J.E. Cochran, H. Yan, E. Gann, C. Hub, R. Fink, C. Wang, T. Schuettfort, C.R. McNeill, M.L. Chabinyc, and H. Ade: Polarized x-ray scattering reveals non-crystalline orientational ordering in organic films. Nat. Mater. 11, 536 (2012) 